\title{
12
}

\section{Seeing Beyond the Dominant Culture}

Perhaps the most useful contribution I can make to a discussion about "seeing beyond the dominant culture" is to offer a critical glance at the concept of ethnic landscapes with special reference to the American scene.

For most of our compatriots in recent times, the term ethnic has acquired a rather limited definition, but I prefer to frame it in a broader and, I believe, much more meaningful way by having it refer to "the ethnie" or, if you please, "the nation." Such a term identifies a fairly large real, or perhaps imagined, community of individuals who cherish a distinctive culture or history and regard their specialness as peculiarly important, setting them apart from other social groups. Such a community may-but often does not-aspire to some degree of political autonomy. If we adopt such a definition, what sorts of ethnic landscapes have ever existed, or are possible, in the United States?

What we find in geographic fact, in some three million square miles of territory sandwiched between Quebec and the borderlands of middle America, is a single dominant culture-one pervasive ethnic group-an entity we can properly label Anglo-American. (To simplify the argument, I am ignoring the closely related Anglo-Canadian community; the interrelationships between our two communities are close, complex, and not yet fully worked out.) The Anglo-American ethnic landscape is the product of the early transfer of various immigrant groups and their cultural baggage from northwest Europe, then a certain set of transformations under the impact of novel environmental and social conditions here, and, subsequently, the automatic acceptance of the resulting package by millions of later arrivals and their progeny. 
The invading Europeans encountered in North America a varied set of genuine preexisting ethnic landscapes that were the result of many generations of cultural revolution. We have only a hazy perception of what most of these humanized places were like in visible, physical terms, and for too many virtually no information at all. Obliteration was the fate of nearly all Native American landscapes, with perhaps only one major regional exception-those scattered but reasonably authentic patches surviving in New Mexico and Arizona. (We can increase the count to two if we consider a large fraction of Alaska.) Elsewhere, the places inhabited or frequented today by Native Americans bear little resemblance to the homelands of their ancestors.

The supremely potent Anglo-American cultural system has its regional variety, of course, and with such variability a distinctive set of regional (but by no means ethnic) landscapes. As it happens, I have spent much of my career exploring these fascinating regional nuances. Thus we have the individualities of New England, the Pennsylvania culture area, the Middle West, southern California, the Mormon culture area, and other special tracts, but all are locked within a single unifying cultural embrace. The nearest approach to a genuinely autonomous ethnic-and it is a close call-is to be found in the persistent particularities of the South. There are also instances of partial hybridization with alien but related cultures, as in Louisiana's Acadiana and that ethnic shatter zone stretching from southern California to the mouth of the Rio Grande. And, of course, the entire system keeps on evolving in response to external stimuli and its own internal logic.

But, despite all the intriguing regional variations upon a central theme and the effects of time, there is really no serious challenge to a pervasive, if largely subconscious, code governing the proper ways in which to arrange human affairs over American space: how to cope with natural habitats; how to design towns, cities, houses, roads, other structures, or cemeteries; how to occupy rural territory; and, in general, how to relate to our surroundings.

If, for the sake of argument, you can accept this reasoning, what thoughts can we entertain concerning the sorts of landscapes set forth in the three previous papers? I discern two different situations, neither of which can inspire very much cheer among those who enjoy visualizing the United States as a multi-ethnic land.

Rina Swentzell's poignant account of the clash of two utterly different mind sets, two irreconcilable ways of dealing with the face of the earth and the things upon it, in Chapter 4 serves to remind us that a conflict that began in the American Southwest more than four hundred years ago has not yet completely played itself out; that there is no solution mutually acceptable to the two contending ethnic groups. When it comes to the crunch, can there be any question as to which party will prevail?

We can only hope, as much for the sake of our own enlightenment as for the 
general cause of ethnic integrity, that some pueblo landscapes will remain intact and endure. Clearly, there is no comfortable answer to the dilemma of such embattled groups surrounded and constantly assaulted by the intrusions of an overbearing national society. But in the setting of the American Southwest, there is the advantage of having some surviving shreds of the preexisting landscape around, in this instance one with special appeal even to outsiders, with which to marshal resistance.

No such advantage was available to those relative latecomers from Asia and Latin America (or the earlier ones from Africa) and from those sections of Europe beyond the zone nurturing the founders of our dominant culture. These immigrants confronted a preformed, predetermined set of rules, a settlement code already locked solidly into the ground and one they could modify only in the more trivial of details.

That was certainly true in the case of the large, reluctant influx of Africans. With a certain amount of luck you may be able to identify a few tangible items that may have had an African origin, or then again you may not. I have in mind such things as the style of some southern African-American church buildings, certain grave decorations, the bare-swept front yard, and some gardening practices. But even the most African of southern rural tracts does not replicate any portion of Nigeria or Ghana, and the urban African-American ghetto could never be mistaken for any neighborhood in an African metropolis.

I enjoy prowling through the so-called ethnic neighborhoods of our cities as much as anyone and looking at whatever is to be seen. But I must confess that $I$ have never been able to identify any non-American ethnic landscape in any American city. There are, of course, particular sections of a city where a particular immigrant group, or its descendants, comprises all or most of the population. And, sure enough, one comes across what are called ethnic markers, such as distinctive shop signs, exotic religious objects in yards or on porches, ephemeral festival decorations, certain cemetery features, an occasional historical monument, or startling new color patterns for houses acquired by Portuguese-Americans and other chromatically adventurous groups (not to mention what the invading Québecois have done with old Yankee farmhouses in New England). Perhaps the closest approximation to an ethnic statement is in ecclesiastical architecture-those alien synagogues, mosques, and non-Protestant church buildings. Upon further scrutiny, however, these structures turn out to be compromised structures, a blending of styles and construction techniques from two contrasting ethnic worlds.

But whatever exotic tidbits one may glean in these "ethnic" neighborhoods are the handiwork of rather temporary sojourners, and we are dabbling with cosmetics instead of basics. The immigrants did not design or build the neighbor- 
hoods and almost inevitably will pass them on some day to other sets of newcomers. The same neighborhood (including its churches) can be recycled through a varied succession of immigrant groups. The textbook sequence of Irish, Germans, Italians, Eastern Europeans, Jews, African-Americans, Hispanics, and East Asians observed in several of our larger metropolises is only one of the actual scenarios.

Moreover, some of these transient groups were not aware of their so-called ethnic identity until they were briefed on the matter by 100 percent Americans. That is what seems to have been the experience of many Italian-Americans, German-Americans, Yugoslavs, African-Americans, and others who previously had little group consciousness beyond that of their village or region in the Old World.

The disconcerting truth would seem to be that we really have no Polish-American, Greek-American, Jewish-American, African-American, or other such ethnic landscapes in any meaningful sense. David Chuenyan Lai has served us well by classifying and describing the various types of Chinatowns in the United States and Canada (see Chapter 6), but here again I must question their authenticity as ethnic expressions. As a matter of fact, Lai reveals the essential visual fakery of such neighborhoods in a single pivotal sentence when he states that "Western architects or contractors built most of the old Chinatown buildings, but they tried to create 'chinoiserie' or exotica by modifying or manipulating standard Western architectural forms."

And, of course, an ever-increasing majority of Chinese-Americans reside in homes and neighborhoods that are outwardly quite indistinguishable from those of old-stock Americans. I invite the reader to inspect the upscale African-American sections of Greater Atlanta or Washington, the predominantly Jewish suburbs of Detroit or Chicago, those tracts of greater Los Angeles frequented by affluent Americans of Japanese or Korean origin, and then show me their ethnic specialness. The moral, of course, is that all these non-WASP folks were expected to conform and melt into the larger physical fabric of American life as fully and rapidly as possible. And the overwhelming majority were only too delighted to do just that.

What we seem to be getting in our latter-day Chinatowns, whatever their historical origins, is fantasy made tangible, a make-believe China as tourist or patron would like to imagine it or the China best calculated to separate the visitor from his cash. They are specimens of a larger tribe of roadside attractions that includes synthetic Wild West frontier towns and those garish Indian villages to be found in western North Carolina's Cherokee country and elsewhere. We also encounter their ilk vicariously, at an even further remove, in movies filmed in North African villages, Mexican plazas, or Polynesian paradises on the back lots of Hollywood movie studios. Any resemblance to cultural reality is strictly accidental. 
This entertainment genre goes back to Chicago's Columbian Exposition of 1893, if not to even earlier events, when an array of exotic villages was concocted for the edification of the visitor. Still vivid in my recollection is the Belgian Village of Chicago's World's Fair of 1933-34 and other absolutely nonmidwestern villages magically erected along the shores of Lake Michigan. The tradition lingers on, after a fashion, in some of our newer theme parks.

In considering the Power of Place project in which Dolores Hayden has been so deeply involved (see Chapter 9), we confront a quite different phenomenon or question: How best to remember, or resurrect and celebrate, ethnic history? As it happens, I am in total personal and ideological sympathy with her didactic strategy and I applaud all such efforts to remind us of a largely forgotten, too often ignominious past-and thus, indirectly at least, to help mend a contemporary world that needs all the healing it can get. But again, I am obliged to express reservations about the ethnic authenticity of whatever landscapes we may be rescuing, restoring, or fabricating.

Hayden's chapter suggests a much vaster problem: How are we as a society to deal with the past in its entirety, not just the ethnic facets thereof? How much is to be preserved or rediscovered? To which fragments of the visible fabric of our daily lives should we cling, and which should we permit to change or disappear? Which elements, if any, should be museumized? How do we join together harmoniously the preservable past with an unruly present? But thereon hangs another book, or rather an endless series of discussions.

Yes, it is certainly important to look beyond the dominant culture, to learn how all those many alien peoples have fared as they tried to cope with that huge, absorbent phenomenon we call the American cultural system. What I question is the effectiveness of examining pseudo-ethnic landscapes as a strategy for getting at cultural adjustment or survival.

Just as is the case with our political and legal systems, we have in the built landscape something thoroughly public-and, to a certain degree, official. It does not take kindly to foreign intrusion or modification, for serious deviance from the norm is simply too offensive to the collective eye. If we wish to explore what is happening with the minority cultures within our borders, we must resort to less visible departments of cultural behavior, to those venues (such as worship, cuisine, social organizations, literature, and the arts) where there is space for experiment, improvisation, and cross-fertilization.

On the other hand, there are other motives for scrutinizing whatever passes for ethnic landscapes in America. Such places fall within the category of the landscapes of entertainment or fantasy. If we really wish to know more about Americans in general, they deserve our earnest attention. 